\title{
EDITORIAL
}

\section{Chronic thromboembolic pulmonary hypertension: advances from bench to patient management}

\author{
Joanna Pepke-Zaba*, Marius M. Hoeper ${ }^{\#}$ and Marc Humbert ${ }^{\uparrow,+, \S}$
}

$\mathbf{0}$ ur understanding of chronic thromboembolic pulmonary hypertension (CTEPH), in terms of its natural history, pathophysiology and management of patients, has greatly improved since the landmark descriptions given by Kenneth Moser and Nina Braunwald [1] more than 40 yrs ago. At that time, small case series were available depicting the clinical features of patients suffering from "long-standing thromboembolic pulmonary hypertension", "chronic massive thromboembolic obstruction" or "chronic obstruction of large pulmonary arteries". The success of a surgical procedure, namely pulmonary endarterectomy (PEA), has transformed this lethal disorder into a potentially curable form of pulmonary hypertension. As a consequence, the referral of cases suitable for surgery has gradually increased with time. At the University of San Diego (San Diego, CA, USA), more than 2,700 PEA procedures have been performed since 1970, the majority over the past 20 yrs [2-4]. European centres have subsequently contributed to broaden the knowledge on the disease [5-7].

30 yrs ago, the frequency of CTEPH as a late complication of acute pulmonary embolism was believed to be very low (0.1$0.5 \%$ ) [8]. Based on recent prospective studies, it is likely that CTEPH is much more common than initially thought (in 1-3.8\% of patients who survived acute pulmonary embolism) [9, 10], potentially leading to as many as 6,000-22,000 new cases annually in the US alone [11]. Early identification of CTEPH is critical as it is the only subgroup of pulmonary hypertension that can potentially be cured by means of surgery. Thus, the search for CTEPH should be an integral part of the diagnostic evaluation of patients with unexplained pulmonary hypertension.

In response to the growing interest in the understanding of the mechanisms and natural history of the disease, the International CTEPH Association (ICA, previously called Association for Research in CTEPH) was founded in 2006 [12]. The first aim of the ICA was to establish epidemiological knowledge on CTEPH, e.g. to identify and evaluate factors that affect survival of patients. In order to fulfil this goal, the ICA initiated an international CTEPH registry in 2007 and early outcomes have recently been published $[13,14]$. This registry has allowed the

*Pulmonary Vascular Diseases Unit, Papworth Hospital, Cambridge, UK. "Dept of Respiratory Medicine, Hannover Medical School, Hannover, Germany. "Université Paris-Sud 11, Faculté de Médecine, ${ }^{+}$AP-HP, Centre de Référence de l'Hypertension Pulmonaire Sévère, Hôpital Bicêtre, Le Kremlin Bicêtre, and ${ }^{5}$ INSERM U999 "Hypertension Artérielle Pulmonaire, Physiopathologie et Innovation Thérapeutique", Centre Chirurgical Marie-Lannelongue, Le Plessis-Robinson, France.

CORRESPONDENCE: J. Pepke-Zaba, Pulmonary Vascular Diseases Unit, Papworth Hospital, Papworth Everard, Cambridge, CB23 3RE, UK. E-mail: joanna.pepkezaba@papworth.nhs.uk establishment of a unique database to support research and education in this under-recognised field of pulmonary vascular medicine.

In June 2011, the ICA organised the International Scientific and Educational Workshop in CTEPH in Cambridge, UK. This workshop was attended by experts in the field of CTEPH from all over the world, including a large number of thoracic surgeons.

A new series in the European Respiratory Journal (ERJ) is entitled "Chronic thromboembolic pulmonary hypertension". It includes articles presenting the current understanding and expert consensus as discussed at the workshop and addresses key issues in the development of a framework for patient management.

The series begins with an article on the pathophysiology of the pulmonary circulation and the right ventricular adaptation by DeLcroix et al. [15]. The next article, by LANG et al. [16], describes the basic mechanisms involved in the vascular remodelling process in CTEPH. Surgical treatment is discussed by JENKINS et al. [17]. Finally, J. Pepke-Zaba and colleagues will discuss medical patient management.

In the current issue of the ERJ, DeLcroix et al. [15] review the current knowledge on vascular and right ventricular remodelling in CTEPH with specific interest in the role of pressure and flow-wave morphology, highlighting the differences between pulmonary arterial hypertension (PAH) and CTEPH. These authors suggest that despite similar loading conditions in CTEPH and PAH, there is proportionally more wave reflection in $\mathrm{CTEPH}$ than in $\mathrm{PAH}$, impacting on pressure and flow-wave morphology.

LANG et al. [16] will examine the available evidence that indicates that CTEPH is primarily caused by venous thromboembolism (VTE), but may occasionally result from in situ pulmonary vascular thrombosis. The authors propose the concepts of "inflammatory thrombosis" and "deficient angiogenesis", in which the pulmonary embolism may be followed by a pulmonary vascular remodelling process modified by infection, immune phenomena, inflammation, circulating and vascular-resident progenitor cells, thyroid hormone replacement or malignancy. Both plasmatic factors (hypercoagulation, "sticky" red blood cells, high platelet counts, uncleavable fibrinogens) and a misguided vascular remodelling process contribute to major vessel and small vessel obliteration.

JENKINS et al. [17] will present guidelines on the assessment of operability, highlighting the critical role of imaging. They 
emphasise that the final decision to operate is still based on the balance between the clot accessibility and the degree of pulmonary hypertension, as assessed by pulmonary vascular resistance. A universal definition of operability is not yet proposed, but a scoring system for the evaluation of the operative risk, morbidity and long-term outcome (PEA score) is discussed as a potentially useful tool to improve the assessment of operability. The authors discuss current techniques for PEA surgery with specific focus on brain protection, post-operative care and residual pulmonary hypertension. Additionally, the organisation of the PEA centres varying in referral patterns, size and expertise and the impact on the surgical outcomes is addressed. The availability of a potential surgical cure for selected patients and recent improvements in peri-operative morbidity and mortality across the world highlight the need for all patients with suspected CTEPH to be referred to an experienced centre for assessment of operability.

Surgery is the treatment of choice for CTEPH but some patients are deemed inoperable. The clinical scenario for these patients is discussed in the final paper of the series where the authors assess the role of medical therapies and, in particular, targeted therapies for PAH in the management of patients with CTEPH.

This series presents an up-to-date, state-of-the-art approach to CTEPH but, at the same time, highlights several controversies in the management of patients. This series emphasises that, with overall increase in pulmonary hypertension awareness, it remains critical to ensure that the potentially curable CTEPH patients are recognised and properly treated. This series is intended to trigger new research projects and trials to prompt additional progress in our understanding of the disease and, as a result, to improve patient care and management.

\section{STATEMENT OF INTEREST}

Statements of interest for all authors can be found at www.erj. ersjournals.com/site/misc/statements.xhtml

\section{REFERENCES}

1 Moser KM, Braunwald NS. Successful surgical intervention in severe chronic thromboembolic pulmonary hypertension. Chest 1973; 64: 29-35.

2 Daily PO, Dembitsky WP, Peterson KL, et al. Modifications of techniques and early results of pulmonary thromboendarterectomy for chronic pulmonary embolism. J Thorac Cardiovasc Surg 1987; 93 : 221-233.

3 Moser KM, Auger WR, Fedullo PF, et al. Chronic thromboembolic pulmonary hypertension: clinical picture and surgical treatment. Eur Respir J 1992; 5: 334-342.

4 Madani MM, Auger WR, Pretorius V, et al. Pulmonary endarterectomy: recent changes in a single institution's experience of more than 2,700 patients. Ann Thorac Surg 2012; 94: 97-103.

5 Dartevelle P, Fadel E, Mussot S, et al. Chronic thromboembolic pulmonary hypertension. Eur Respir J 2004; 23: 637-648.

6 Bonderman D, Jakowitsch J, Adlbrecht C, et al. Medical conditions increasing the risk of chronic thromboembolic pulmonary hypertension. Thromb Haemost 2005; 93: 512-516.

7 Condliffe R, Kiely DG, Gibbs JS, et al. Improved outcomes in medically and surgically treated chronic thromboembolic pulmonary hypertension. Am J Respir Crit Care Med 2008; 177: 1122-1127.

8 Fedullo PF, Auger WR, Kerr KM, et al. Chronic thromboembolic pulmonary hypertension. N Engl J Med 2001; 345: 1465-1472.

9 Becattini C, Agnelli G, Pesavento R, et al. Incidence of chronic thromboembolic pulmonary hypertension after a first episode of pulmonary embolism. Chest 2006; 130: 172-175.

10 Pengo V, Lensing $\mathrm{AW}$, Prins $\mathrm{MH}$, et al. Incidence of chronic thromboembolic pulmonary hypertension after pulmonary embolism. N Engl J Med 2004; 350: 2257-2264.

11 Tapson VF, Humbert M. Incidence and prevalence of chronic thromboembolic pulmonary hypertension: from acute to chronic pulmonary embolism. Proc Am Thorac Soc 2006; 3: 564-567.

12 International CTEPH Association. www.cteph-association.org Date last updated: October 2012. Date last accessed: November 14, 2012.

13 Mayer E, Jenkins D, Lindner J, et al. Surgical management and outcomes of patients with chronic thromboembolic pulmonary hypertension: results from an international prospective registry. J Thorac Cardiovasc Surg 2011; 141: 702-710.

14 Pepke-Zaba J, Delcroix M, Lang I, et al. Chronic thromboembolic pulmonary hypertension (CTEPH): results from an international prospective registry. Circulation 2011; 124: 1973-1981.

15 Delcroix M, Vonk-Noordegraaf A, Fadel E, et al. Vascular and right ventricular remodelling in chronic thromboembolic pulmonary hypertension. Eur Respir J 2013; 41: 224-232.

16 Lang IM, Pesavento R, Bonderman D, et al. Risk factor and basic mechanisms of CTEPH: a current understanding. Eur Respir J 2013; [Epub ahead of print DOI: 10.1183/09031936.00049312].

17 Jenkins DP, Madani M, Mayer E, et al. Surgical treatment of CTEPH. Eur Respir J 2013; [Epub ahead of print DOI: 10.1183/ 09031936.00058112]. 